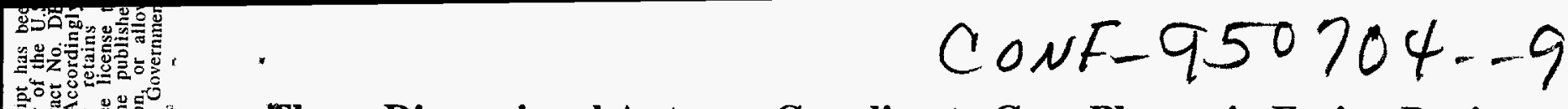

\title{
Three-Dimensional Antenna Coupling to Core Plasma in Fusion Devices
}

\author{
M.D. Carter, E.F. Jaeger, D.C. Stallings, J.D. Galambos, D.B. Batchelor, C.Y. Wang, \\ Oak Ridge National Laboratory, Oak Ridge, TN 37831-8071
}

\section{Introduction}

A complete understanding of the RF physics from the launcher to the plasma core is required to fully analyze RF experiments and to evaluate the performance of RF antenna designs in ITER. This understanding requires a consistent model for the RF power launching system, propagation and absorption through the edge region, and the response of the core plasma to the RF power. As a first step toward such a model, the three-dimensional (3D) antenna modeling code, RANT3D [1], has been coupled with the reduced order full wave code, PICES [2]. Preliminary results from this model are presented in this paper for parameters similar to those found in the DIII-D [3] experiment.

The RANT3D code solves Maxwell's equations in vacuum for a collection of connected rectangular waveguide sections. The geometry of the antenna box, the septa between straps, and other features of the tokamak first wall are modeled by these waveguide sections. The antenna is driven by a set of prescribed currents [4] on the main current straps. Return currents in the sidewalls and septa are determined by conducting boundary conditions and are calculated self-consistently. The plasma boundary is determined by a generalized impedance matrix [5]. Fig. 1 shows the RANT3D model typically used for the DIII-D antenna.

The PICES code uses a reduced order approximation and a poloidal mode expansion to generate a set of coupled differential equations that are solved by finite differences. The code calculates the current driven by fast waves using the absorbed power in a current drive model by Ehst [6].

Both RANT3D and PICES have been separately benchmarked with experimental data [1,2]. For ICRF current drive experiments, the combined model can be used to generate the launched current drive spectrum in $3 \mathrm{D}$ and follow the power into the plasma core. Results from the combined codes are presented for heating and current drive scenarios in the next section.

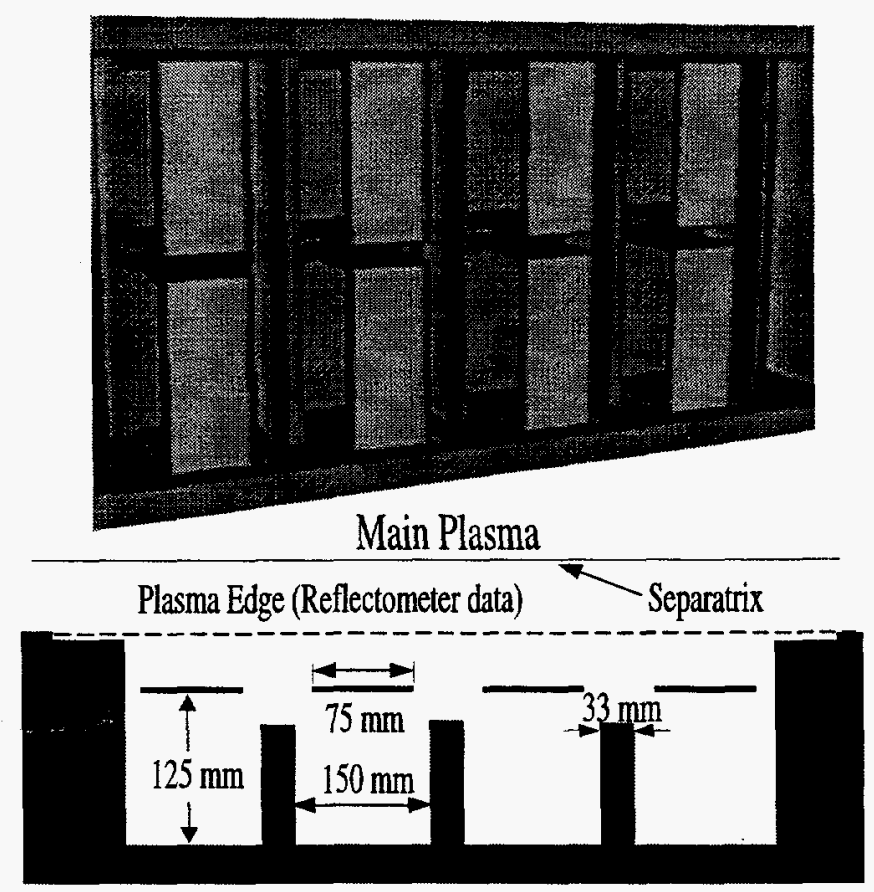

Fig. 1 Typical RANT3D antenna model for DIII-D. 


\section{DISCLAIMER}

This report was prepared as an account of work sponsored by an agency of the United States Government. Neither the United States Government nor any agency thereof, nor any of their employees, makes any warranty, express or implied, or assumes any legal liability or responsibility for the accuracy, completeness, or usefulness of any information, apparatus, product, or process disclosed, or represents that its use would not infringe privately owned rights. Reference herein to any specific commercial product, process, or service by trade name, trademark, manufacturer, or otherwise does not necessarily constitute or imply its endorsement, recommendation, or favoring by the United States Government or any agency thereof. The views and opinions of authors expressed herein do not necessarily state or reflect those of the United States Government or any agency thereof. 


\section{DISCLAIMER}

Portions of this document may be illegible in electronic image products. Images are produced from the best available original document. 
"The interface between the two codes is done in two steps. The first step is to perform a RANT3D calculation using a slab code such as PLASMAIMP [7] (cold) or GLOSI [8] (warm) for the plasma response. The second step is to take the tangential electric fields from the RANT3D calculation and use these fields as the outer boundary condition for the PICES code.

In the first step, the PLASMAIMP and GLOSI codes fresently assume an outgoing boundary condition near the center of the plasma. This approximation is reasonable if the power reflected directly back to the antenna by the inside wall of the tokamak is small. The coupling of poloidal modes by toroidal effects in the plasma is ignored in the impedance matrix at this point; however, the $3 \mathrm{D}$ geometry of the antenna ultimately couples all of the poloidal and toroidal modes in the RANT3D calculation. Both slab codes retain both field polarizations and are periodic in both the toroidal and poloidal directions. The first step produces electric field components tangent to the tokamak first wall that are zero everywhere except in the neighborhood of the antenna opening as shown in Fig. 2.

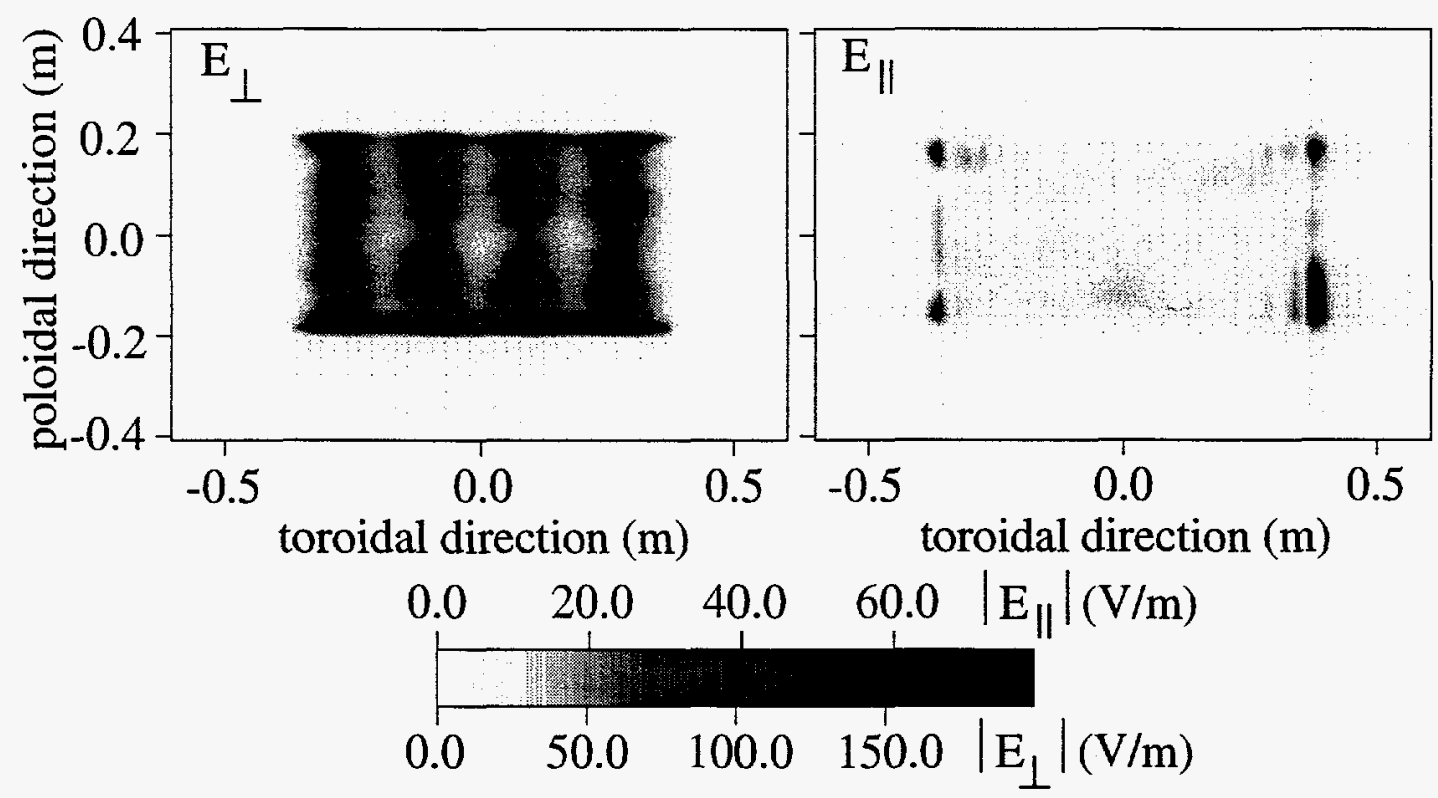

Fig. 2 Image of tangential electric field components from RANT3D model used as boundary condition for PICES code. 'DIIID-like' parameters were used for this calculation $\pi / 2$ phase difference between straps. The values marked on the palette correspond to 1 Amp of current driven in each current strap.

In the second step, the electric field components tangent to the first wall from the RANT3D solution are mapped onto a surface having the same shape as the last closed flux surface given by the VMEC [9] code. The tangential fields on this surface then provide the outer boundary condition for the PICES code.

\section{Results}

For the model shown in Fig. 1, each of the current strap segments are in phase poloidally and have a phase difference of $\pi / 2$ toroidally for the current drive modeling. Fig. 2 shows typical values of the modulus of $E_{\perp}$ and $E_{\|}$generated by RANT3D for the PICES boundary 
using a warm plasma impedance matrix from GLOSI. The tangential electric fields are zero outside the opening of the antenna because of the conducting wall. Thus, only the localized fields in front of the antenna port contribute to the PICES boundary condition. Note the strong localization of the parallel electric field component near the edge and corners of the port.

Fig. 3 shows a poloidal cross-section of the electric fields and absorbed power calculated by PICES using the electric field boundary condition obtained from RANT3D. The localized nature of the electric field boundary condition provided by RANT3D is preserved in PICES.
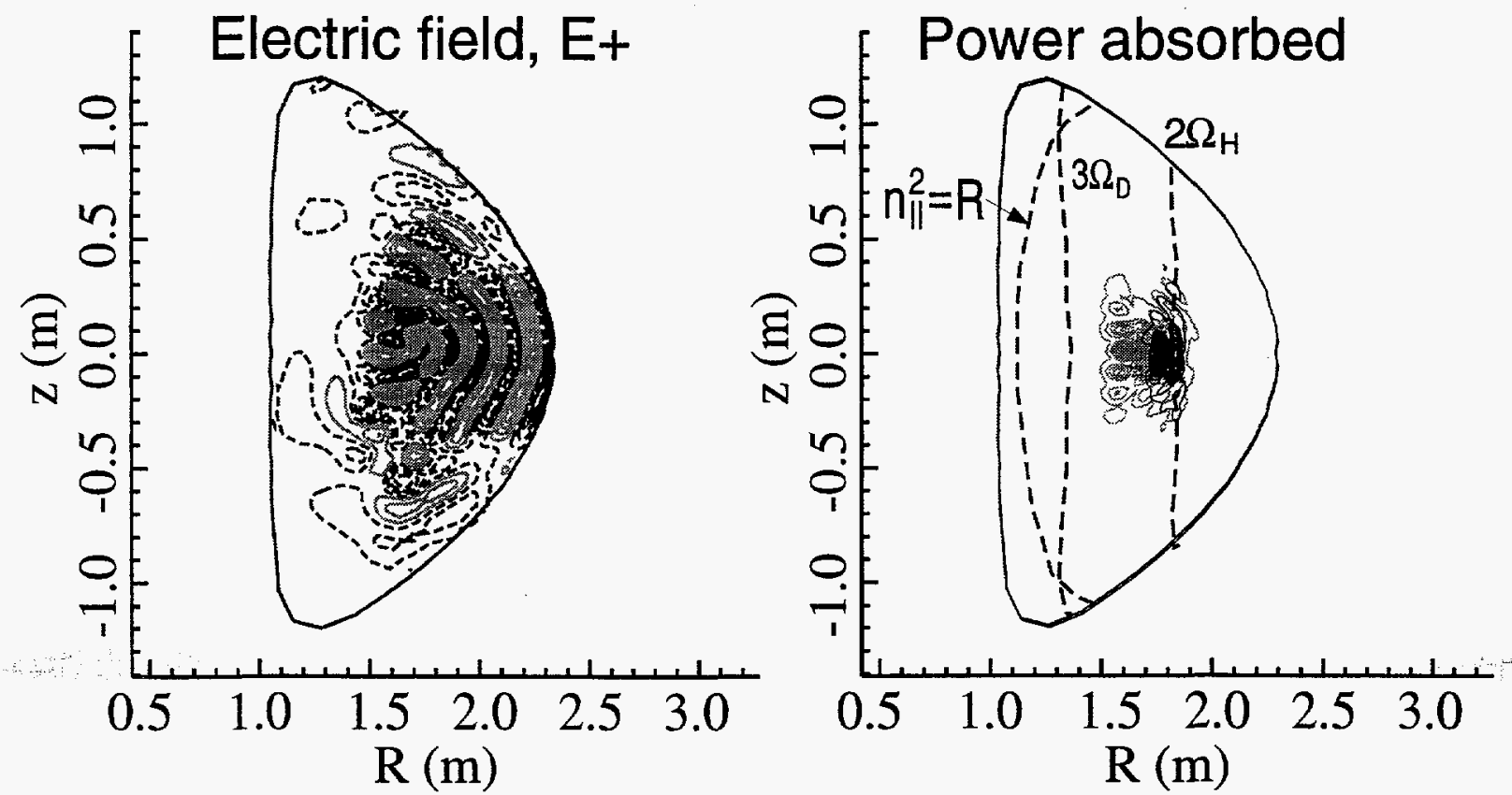

Fig. 3 Electric field and absorbed power for the $60 \mathrm{MHz}$ current drive scenario using 'DIII-D-like' parameters.

A study of the parasitic absorption by the second harmonic hydrogen resonance was made because it is difficult to remove all traces of a hydrogen impurity in the experiment. For the 60 $\mathrm{MHz}$ case shown in Fig. 3, the power absorbed by the second harmonic hydrogen resonance is $-50 \%$ with $4 \%$ hydrogen, but drops to $-30 \%$ with $1 \%$ hydrogen. Increasing the frequency to $90 \mathrm{MHz}$ reduces the hydrogen absorption to $<10 \%$ for a $1 \%$ hydrogen concentration.

Fig. 4 shows the driven current caused by fast wave absorption by electrons. A driven current of $60 \mathrm{kA}$ is predicted from the model for $0.8 \mathrm{MW}$ of coupled power at $60 \mathrm{MHz}$. An additional current of $68 \mathrm{kA}$ is predicted when $0.6 \mathrm{MW}$ of power is added at $90 \mathrm{MHz}$. The increase in efficiency from $\gamma=0.02 \mathrm{~A} /\left(\mathrm{Wm}^{2}\right)$ for $60 \mathrm{MHz}$ to $\gamma=0.03 \mathrm{~A} /\left(\mathrm{Wm}^{2}\right)$ for the $90 \mathrm{MHz}$ scenario is largely due to the reduced cyclotron absorption by the hydrogen impurity. Experimental efforts are underway to determine the accuracy of these modeling results [3].

The first pass absorption for the waves in these scenarios was $14 \%$ and $10 \%$ for the $60 \mathrm{MHz}$ and $90 \mathrm{MHz}$ cases respectively. The low first pass absorption causes interference patterns that may be responsible for the the depression of the driven current density near the axis in Fig. 4 . The reduced current density on axis is caused by a reduced value of $E_{\|\|}$near the axis. 


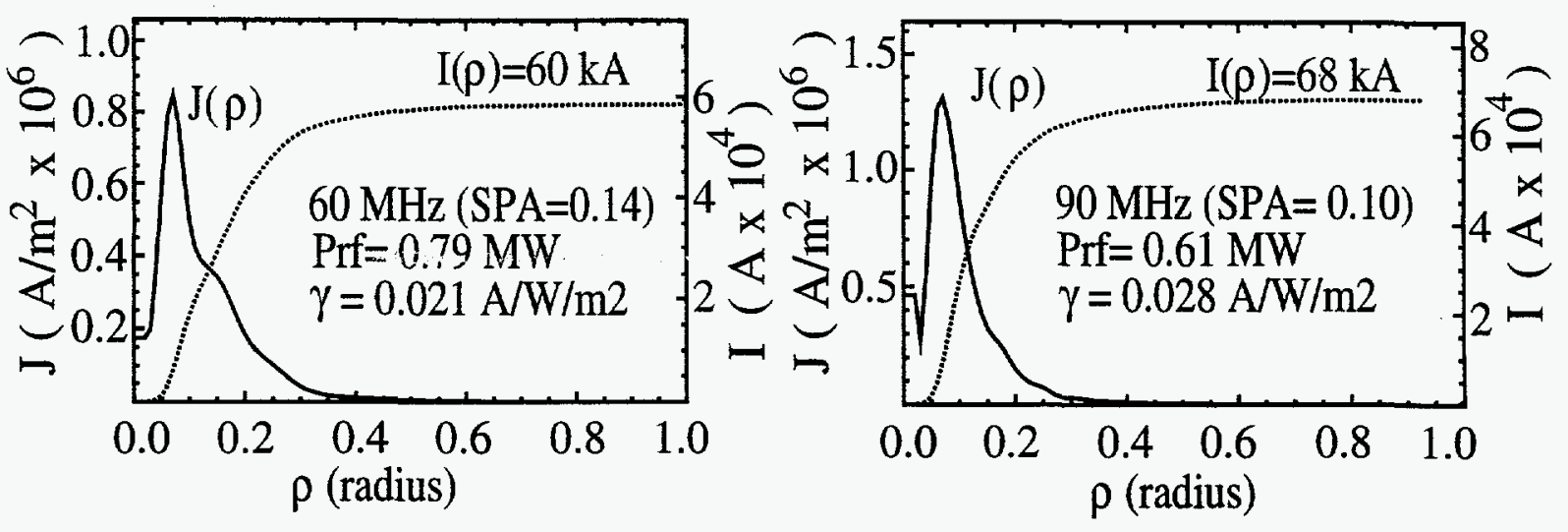

Fig. 4 Deposited current for the $60 \mathrm{MHz}$ and $90 \mathrm{Mhz}$ scenarios from PICES using a boundary condition provided by the RANT3D code.

\section{Summary}

The coupling of the RANT3D and PICES codes represents a first step toward the complete modeling of RF power delivery systems from the antenna to the core plasma. The RANT3D code uses a 3D antenna model with detailed information in the edge plasma region to provide a realistic 'footprint' for the antenna for input to the full-wave PICES code. The codes have been used to model fast wave current drive for plasma parameters similar to those found in the DIII-D experiment. The results show that both $60 \mathrm{MHz}$ and $90 \mathrm{MHz}$ scenarios should be able to drive current in the 60 to $70 \mathrm{kA}$ range with less that $1 \mathrm{MW}$ of input ICRF power. The efficiency of the $90 \mathrm{MHz}$ current drive scenario is $\sim 50 \%$ higher than the $60 \mathrm{MHz}$ scenario because of reduced absorption at the second harmonic resonance of the residual hydrogen species.

\section{References}

[1] Carter, M.D. et al.,'Three-Dimensional Modeling of ICRF Launchers for Fusion Devices,' to be published in Nucl. Fusion (1995).

[2] Jaeger, E.F., Batchelor, D.B., Stallings, D.C., Nucl. Fusion 33179 (1993).

[3] Forest, C.B. et al., 'Experimentally Determined Profiles of Fast Wave Current on DIII-D,' Poster II3, 11th Topical Conference on Radio Frequency Power in Plasmas, AIP Conf. Proc., Palm Springs, CA, May 1995.

[4] Ryan, P.M. et al., 'Integrated Design and Analysis of RF Heating and Current Drive Systems', Invited paper, 11th Topical Conference on Radio Frequency Power in Plasmas, AIP Conf. Proc., Palm Springs, CA, May 1995.

[5] Brambilla, M., Nucl. Fusion 28549 (1988).

[6] Ehst, D.A., Karney, C.F.F., Nucl. Fusion 311933 (1991).

[7] Stallings, et al., Bull. Am. Phys. Soc. 39(7), 1628 (1994)

[8] Wang, C.Y., Report number ORNL/TM-12923, NTIS, Springfield, VA, http://www.fedworld.gov/ntis/ntishome.html (1995).

[9] Hirshman, S.P., Lee, D.K., Comput. Phys. Commun. 31161 (1986). 